\title{
Obituary: Dick van der Helm, an internationally recognized siderophore researcher and a crystallographer
}

\author{
Hans J. Vogel
}

Received: 15 June 2010/Accepted: 16 June 2010/Published online: 2 July 2010

(C) Springer Science+Business Media, LLC. 2010

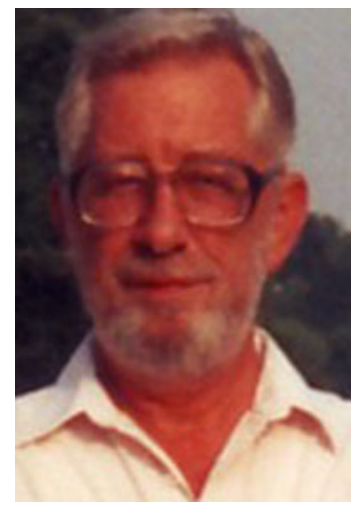

Professor Dick van der Helm, one of the pioneers of the structural siderophore field, passed away on April 28, 2010, aged 77. Dick was born on March 16, 1933 in Velsen, the Netherlands and after completing his regular primary and secondary school education he enrolled at the University of Amsterdam. He obtained the Dutch equivalents of the Bachelors and Masters degrees in 1952 and 1956, respectively. He then worked abroad at Indiana University for a number of years but he briefly returned to his alma mater to obtain his Doctoral degree in crystallography in 1960. Of particular importance during his further crystallography training were the postdoctoral years from

H. J. Vogel $(\bowtie)$

University of Calgary, Calgary, Canada

e-mail: vogel@ucalgary.ca
1959 to 1962 which he spent working with Lindo Patterson at the Institute for Cancer Research in Philadelphia. During this time important computer programs for the analysis of crystallographic data were developed that have since been used extensively by numerous scientists worldwide. Dick has worked for most of his career (from 1962 to 2002) at the University of Oklahoma in Norman, where he was a highly valued member of the Chemistry department. He rapidly rose through the ranks and he was appointed as a George Lynn Cross Research Professor in 1977; this is the highest research honor that a faculty member can receive from the University of Oklahoma, and it reflects Dicks' national and international recognition over a number of years. Dick has also been a recipient of an NIH Career development award from 1969 to 1974 and the Oklahoma Scientist award in 1980.

Shortly after moving to Norman, Oklahoma, Dick became fascinated by the structures of siderophores and related iron-chelating compounds. His research group has purified and structurally characterized many different siderophores and through this work they have helped to firmly establish the chemical features and the preferred coordination chemistry that characterize a potent naturally occurring iron chelator that can be used to fulfill the need for the essential element iron of micro-organisms such as bacteria or fungi. Glancing over Dick's publication record from the 1960's, 1970's and the early 1980's reads like a 'Who's Who of the ferric-siderophore world' as we 
currently know it: ferrichrome, ferrioxamine, pseudobactin, anguibactin, agrobactin, just to name a few. This work helped to firmly establish the important biological role of siderophores and it brought him in contact with many microbiologists and other scientists that were studying bacterial and fungal iron uptake pathways. During these years Dick also spent a sabbatical leave at the University of Groningen in the Netherlands, to further hone his skills as a single crystal crystallographer. Moreover, in the early parts of his career Dick also played an important role in various committees of the American Crystallographic Association and in 1978 he organized and hosted their national meeting in Norman. Dick's research on siderophores extended well into the 1990's and also included some related studies on potentially clinically useful iron chelators.

In 1984 Dick and his family spent a sabbatical year in Tuebingen, Germany, where he worked together with Guenther Winkelmann. During this extended visit he also interacted with many other European researchers, most notably the other members of the Tuebingen "IronMen": Volkmar Braun and Klaus Hantke. It was after this experience that Dick decided to start working towards solving the structures of the proteins that are involved in siderophore uptake in bacteria. Although Dick and his group already reported on the purification and initial crystallization of the FepA outer membrane siderophore-receptor in 1989, it took an additional 10 years before the protein crystals diffracted well enough and the first structures for these dedicated outer membrane transporters could be reported. By this time Dick had decided to team-up with the Deisenhofer group in Dallas and this fruitful collaboration resulted in the high-resolution structures of the bacterial enterobactin transporter FepA and the iron-citrate carrier FecA from $E$. coli. These two early membrane protein structures should be considered as excellent achievements and they are still highly cited contributions. This seminal work triggered a flurry of activity and currently almost 50 different outer membrane transporter structures have been deposited in the protein database. Around the same time crystal structures for periplasmic siderophore-binding proteins also became available as well as several unexpected structures of siderophores bound to the human lipocalin protein, which is now called 'siderocalin'. The latter serendipitous discovery has opened up a whole new area in siderophore biology. Dick was clearly delighted by these developments and the renewed and widening interests in the role of siderophores. With help from Ranjan Chakroborty, he spent the last few years of his career studying various mutants of the bacterial outer membrane siderophore transport proteins, trying to further understand their mechanism of action. As one of the long-serving members of the Editorial Board of the BioMetals journal Dick remained actively in involved in science until very recently, and he took great pride in keeping on top of the current scientific literature in this area.

Perhaps not so well known among his many siderophore friends and colleagues, in addition to working on iron uptake in microorganisms, Dick also had a very strong interest in studying various biologically active compounds that were isolated from marine organisms. Again he used a structural crystallography-based approach, complemented in this case by theoretical molecular mechanics and molecular dynamics calculations. A portion of this research was focused on potential anticancer compounds and the biological aspects of this work were carried out in the laboratories of his Oklahoma colleagues Fritz Schmitz and Al Weinheimer. Altogether Dick has had an extremely productive research career, in which he was supported by the NIH for 30 years and published well over 300 original research papers. His scientific work has already been cited 7000 times. All of these are clearly excellent achievements.

Dick has successfully mentored a large number of graduate students and postdoctoral fellows, some 50 in total. He also took an active role in mentoring junior faculty members. In his research laboratory Dick promoted independent thinking, by challenging his trainees to come up with novel ideas and solutions. Dick was a well-trained physical chemist and he paid close attention to the accuracy of the experimentation and the proper interpretation of experimental data. While he was always extremely happy with a successful experiment, he remained a very careful scientist who was very hesitant about extrapolating the results too far. Dick also had a passion for undergraduate teaching; he is fondly remembered by many trainees as a dedicated instructor and several students have benefitted greatly from doing research projects in his laboratory. He recently 
commented that in his retirement he missed the interactions with the young students.

Following his retirement from the University of Oklahoma, Dick moved to Vancouver Island in Canada, where he was associated for a few years with the Department of Biochemistry at the University of Victoria. When he stepped away from this position he and his wife moved to Ferndale (WA), and more recently to Cincinnati $(\mathrm{OH})$. As he was gradually winding down his research activities, Dick developed a passion for playing golf. He spent a lot of time on the golf course and he was in good physical shape. Dick also had a dry sense of humor: once during a game of golf which was played during the Oregon Biometals meeting that was organized by Jorge Crosa, he remarked that experienced crystallographers perhaps did not hit the ball as far as many younger scientists, but that they seemed to have their $\mathrm{x}, \mathrm{y}$ and $\mathrm{z}$ coordinates better under control. Needless to say, Dick, with his methodical and accurate golf game convincingly beat all his partners that day!
Unfortunately we won't have a chance anymore to take him up on his offer for a rematch.

Dick and his wife Louise loved to travel and many of us have had the pleasure of interacting with Louise as she often accompanied him to the international Biometals meetings and other scientific gatherings. Dick is survived by his wife, and by all 6 of his children (Marijke, Rebecca, Michael, Anneke, Dick and Mark) and his 9 grandchildren. We wish them well in this difficult time. Dick will also be greatly missed by many scientific colleagues. Not only did we loose a friend, but also his research work has had a major impact on the field and he has been a source of inspiration to many of us. A few years ago, one of Dick's former undergraduate student researchers (John Burks) established a Dick van der Helm Scholarship fund in his honor (\#42061, www. oufoundation.org) and contributions, appropriately labeled as "in memory of Dick van der Helm", are of course welcome. 